ISSN: 1641-4713; e-ISSN: 2081-1160

DOI: https://doi.org/10.36551/2081-1160.2021.28.7-30

\title{
Las Actas de la Junta Militar: Hallazgo, archivo y agenda secreta (Argentina, 1976-1983)
}

\author{
The minutes of the Military Junta: Findings, archive and secret agenda \\ (Argentina, 1976-1983)
}

Natalia García

Instituto de Investigaciones "Dr. Adolfo Prieto", Facultad de Humanidades y Artes

Universidad Nacional de Rosario, Argentina

ORCID iD: https://orcid.org/0000-0003-3204-561X

E-mail: nataliagr5@gmail.com

Recepción: 22.05.2021

Aprobación: 20.09.2021

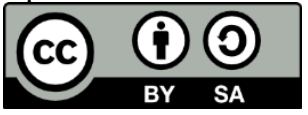

Resumen: El presente artículo sistematiza la totalidad del temario tratado en las reuniones secretas de la Junta Militar argentina (1976-1983), según registran las 280 actas encontradas en el año 2013. En principio, se describen las especiales circunstancias del hallazgo, sus principales rasgos archivísticos y el tratamiento político decidido para su accesibilidad. El trabajo se concentra en la densidad del acervo clandestino desde una perspectiva aproximada y panorámica, a los efectos de identificar las áreas gubernamentales priorizadas en la agenda del máximo órgano responsable del terrorismo de Estado. Con ello, se desagregan y analizan las coyunturas atravesadas, así como las respuestas y propuestas que debatieron los comandantes de las Fuerzas Armadas, los Secretarios Generales y representantes del Poder Ejecutivo Nacional, el Estado Mayor Conjunto, la Comisión de Asesoramiento Legal, la Secretaría General de la Presidencia de la Nación y ministros de diferentes carteras. Para su abordaje metodológico, los cuantiosos datos explorados se reúnen y ordenan en las siguientes dimensiones: represión ilegal, objetivos políticos, relaciones exteriores, proyectos legislativos, políticas económicas, asuntos protocolares, corporación militar y sistema educativo. Tales categorizaciones expresan los resultados de la saturación documental en cada tema, igualmente graficados según los porcentajes hallados.

Palabras clave: Historia reciente, Junta Militar, actas secretas, hallazgos documentales, políticas archivísticas 


\begin{abstract}
This article systematizes the entire agenda discussed in the secret meetings of the Argentine Military Junta (1976-1983), as recorded in the 280 minutes found in 2013. First, we describe the special circumstances of the discovery, its main archival features and its political treatment for accessibility. The work focuses on the density of the clandestine collection from an approximate and panoramic perspective, in order to identify the government areas prioritized in the agenda of the highest body responsible for State terrorism. With this, we analyze the situations that were crossed, the responses and proposals debated by the commanders of the Armed Forces, the General Secretaries and representatives of the National Executive Power, the Joint Chiefs of Staff, the Legal Advisory Commission, the General Secretariat of the Presidency of the Nation and ministers from different areas. For the methodological approach, the explored data were gathered and arranged in the following dimensions: illegal repression, political objectives, foreign relations, legislative projects, economic policies, protocol affairs, military corporation and educational system. Such categorizations express the results of the document saturation in each topic, also graphed according to the percentages found.
\end{abstract}

Keywords: Recent history, Military Junta, secret acts, documentary findings, archival policies

\title{
INTRODUCCIÓN
}

El 24 de marzo de 1976 comenzó en la Argentina una dictadura que no tuvo precedentes respecto de las anteriores durante todo el siglo $\mathrm{XX}^{1}$. Se trató entonces de un terrorismo de Estado que planificó y sistematizó una maquinaria criminal sintetizada en la figura de la Desaparición Forzada de Personas y en la diseminación de Centros Clandestinos de Detención y Tortura (CCDyT $)^{2}$. Siguiendo los estudios de Canelo (2012a, 2016), el gobierno de facto autodenominado Proceso de Reorganización Nacional o PRN se caracterizó por la ambición de institucionalizar un nuevo ciclo histórico o re-fundacional que sopesaba las lecciones dejadas por dictaduras anteriores y regímenes castrenses contemporáneos a ella como el de Chile entre 1973 y1990, y Uruguay desde 1973 a 1985. En tales objetivos, no se limitó a la estructura disponible desde el Poder Ejecutivo Nacional -el denominado PEN-, sino que creó un conjunto de organismos

\footnotetext{
${ }^{1}$ Se sucedieron seis golpes de Estado: 1930, 1943, 1955, 1962, 1966 y 1976. Tras el derrocamiento del presidente Juan D. Perón en 1955, se abrió un ciclo de fuerte inestabilidad institucional que produjo la alternancia de gobiernos democráticos y periodos de censura y autoritarismo que recrudecieron en la medida en que las propias Fuerzas Armadas se volvieron actores clave del juego político.

${ }^{2}$ Los CCDyT fueron lugares utilizados por las Fuerzas Armadas y de seguridad del Estado de forma secreta y clandestina para la detención, tortura y exterminio de las personas secuestradas en operativos ilegales. A la fecha, se han identificado unos 340 Centros pero la cifra asciende a 762 si se consideran dependencias transitorias de reclusión ilegal. Ver más en: https://www.argentina.gob.ar/derechoshumanos/sitiosdememoria/mapacentrosclandestinos. Recuperado el 17 de septiembre de 2021.
} 
encabezados por la Junta Militar-JM- u Órgano Supremo de la Nación ${ }^{3}$, asistida por la Comisión de Asesoramiento Legislativo -CAL- y la estratégica Secretaría General de la Presidencia -SGP-. Igualmente, sostuvo dos directivas primarias: un reparto estatal equilibrado entre las FF.AA. y la supremacía de la Junta por sobre del PEN.

El presente trabajo se propone sistematizar la totalidad del temario tratado en las actas secretas de la JM parcialmente analizadas en publicaciones anteriores (Canelo, 2016; Canelo \& Franco 2015; Canelo et al., 2016; Franco, 2014). Dado la densidad del acervo hallado en el año 2013, el problema se aborda desde una perspectiva aproximada y panorámica guiada por las siguientes preguntas: ¿qué temas encabezaron la agenda clandestina?; ¿cuáles fueron las áreas de gobierno priorizadas?; ¿qué problemas y coyunturas contextuales llegaron al órgano soberano?; ¿qué respuestas y propuestas circularon en aquellas reuniones?

Las características de estos originales materiales y las especiales circunstancias de su hallazgo se reseñan en el primer apartado detallando sus principales rasgos archivísticos y el tratamiento político decidido en la singularidad del fondo clasificado como Secreto, Confidencial y Reservado. En lo inmediato, se avanza sobre las referencias básicas que hacen al funcionamiento burocrático y dinámica organizacional de la Junta en aquellos años, según se desprende de las fuentes militares, atendiendo a dos tensiones que transversalmente recorren el periodo: el esquema de poder y el problema del internismo castrense.

Los resultados de la indagación se presentan a lo largo de seis apartados que constituyen los principales aportes del trabajo. Los cuantiosos datos explorados se reúnen y ordenan desde las siguientes categorías: represión ilegal, objetivos políticos, relaciones exteriores, proyectos legislativos, políticas económicas, asuntos protocolares, corporación militar y sistema educativo. Tales dimensiones no resultan de una construcción previa ni arbitraria, sino que expresan la correspondiente saturación documental; es decir, emergen de identificar la recurrencia de estos temas en la agenda de los comandantes. Para una mejor comprensión de la variable cuantitativa, en cada caso se suman gráficos que sintetizan los porcentajes hallados.

\footnotetext{
${ }^{3}$ También denominada Junta Militar de Gobierno o Junta de Comandantes Generales, estuvo integrada por los titulares de las tres fuerzas armadas. Indistintamente, nos referiremos a ella como Junta Militar, Junta o JM. Para Actas de la Junta Militar, se abreviará Actas.
} 


\section{EL HALLAZGO CÓNDOR: ENTRE LA VOLUNTAD Y LA CONTINGENCIA}

El 31 de octubre de 2013 se produjo el inesperado encuentro de las 280 actas secretas de la Junta Militar ubicadas en el subsuelo del emblemático edificio Cóndor de la Fuerza Aérea Argentina. Sin lugar a dudas, se trataba de uno de los hallazgos más importantes de las últimas décadas por su significación histórico-política y por sus características archivísticas. Las 1.500 unidades de conservación fueron localizadas en su estado original, cumpliéndose con ello los principios de identificación y procedencia que ciertamente facilitó la inmediata labor de preservación, sistematización y análisis genérico del corpus. En pocos meses, las fuentes fueron publicadas en formato papel y digital distribuidos en seis tomos ${ }^{4}$, siendo un hecho harto singular para el tratamiento de documentos de naturaleza clandestina (Da Silva Catela, 2002; González Quintana, 1998). Es decir, no se siguieron las regulaciones legales y acuerdos institucionales-archivísticos hasta entonces ensayados (Nazar, 2007), sino que se permitió el acceso o descarga automática sin mediación de terceros ni restricciones en los datos tales como omisiones o tachaduras.

En oportunidad del acto político que comunicó el trascendental hecho el día 4 de noviembre de 2013, el ministro de Defensa Ing. A. Rossi hizo saber que el mismo no respondía a una investigación ordenada por el Poder Judicial, tal y como sucediera en casos similares enmarcados en una política de justicia (Balé, 2018) destinada a juzgar y condenar a miembros de las FF.AA. sospechados de cometer delitos de lesa humanidad. Por el contrario, en este episodio el Brigadier Gral. Mario Callejo dio aviso del hallazgo sin reveses ni ocultamientos. Para el ministro, el gesto del Jefe del Estado Mayor se inscribía en la propia materialidad documental, pues, sin aquella "decisión voluntaria (...) nadie se hubiese enterado nunca de la existencia de estas actas" .

Las referencias comentadas indican que dos rasgos, a priori antagónicos, merodean el descubrimiento de la clandestinidad en este y similares acontecimientos: la contingencia y la voluntad. Por un lado, el componente azaroso en la localización de fondos clandestinos es un asunto repetido en las últimas dos décadas partiendo, por caso, del llamado Archivo BANADE en el año 2000 cuando, "de manera aparentemente casual, un empleado del Ministerio del Interior encontró una cantidad de papeles amontonados en una bóveda del ex Banco Nacional de Desarrollo"

\footnotetext{
${ }^{4}$ Disponible en: https://www.argentina.gob.ar/defensa/archivos-abiertos/centro-de-documentos-digitalizados/Fondo-Junta-Militar. Recuperado el 14 marzo de 2021.

${ }^{5}$ Actas, I: Prólogo presentación, 10, 2014 (Fondo, Tomo, Sección, Página, Año).
} 
(Invernizzi \& Gociol, 2003, p. 25) ${ }^{6}$. Desde entonces asistimos a situaciones análogas que llegan a fechas muy recientes como los hallazgos acaecidos en la Ciudad Autónoma de Buenos Aires en septiembre de 2020 y en la provincia de Santa Fe apenas dos meses después. Este último se produjo en una vivienda particular "cuando un inquilino (...) encontró documentación en una habitación ubicada en la terraza", según detalló en las crónicas la Dra. Lucila Puyol, Secretaria de DDHH y Diversidad en dicha jurisdicción? . En Buenos Aires, el encuentro "accidental" y "estremecedor" se sustanció en la Secretaría de Planificación de la Agencia Federal de Inteligencia ${ }^{8}$.

Ciertamente, la contingencia es constitutiva de la Historia y los espacios que custodian sus restos, como también encarnan un lugar social donde se permiten o prohíben enunciados y prácticas (Ricoeur, 2004). En estas cambiantes posibilidades se recuesta la buena voluntad de Callejo; después de todo, si la revelación de las Actas es deudora de su decisión, ¿a qué se debe entonces la determinación de no proseguir con el consabido pacto de silencios de las Fuerzas? ${ }^{9}$

En el caso argentino, la permanente lucha de los organismos de Derechos Humanos acude como primera respuesta. Pero también es consecuencia de las políticas de Estado en materia archivística en lo particular del Ministerio de Defensa de la Nación Argentina - conocido también por su acrónimo-MDNA tras la aplicación del decreto $\mathrm{N}^{\circ} 4 / 2010^{10}$ que relevó de la clasificación de seguridad a toda información vinculada con el accionar de las FF.AA. en aquellos años. De igual modo, cabe considerar las ulteriores normativas que habilitaron el acceso

\footnotetext{
${ }^{6}$ Contenía más de 600 documentos que informaban las tareas de inteligencia destinadas a la censura cultural montada en las oficinas comandadas por el Gral. A. Harguindeguy (1976-1981).

${ }^{7}$ Se trata de cuantiosa documentación comprendida entre los años 1968-1996 que a priori incluye el accionar del Departamento de operaciones de la provincia, el D3, el D5 y el Departamento Judicial de la Policía de Santa Fe y de la ciudad de Rosario, entre otros; esto es, estamentos neurálgicos de la "comunidad informativa" en sus tareas de espionaje coordinados por la ex Dirección General de Informaciones. Ver más en: https://sinmordaza.com/noticia/156301-lucila-puyol-brindo-detalles-del-importante-hallazgo-de-documentacion-relacionado-a-la-dictadura.html. Recuperado el 14 marzo de 2021.

8 En un verdadero inédito material, se destaca la aparición de un libro que exhibe más de 500 fotografías de víctimas de la persecución política, tortura y desaparición forzada. Ver más en: https://www.pagina12.com.ar/294499-archivos-de-la-dictadura-la-afi-entrego-el-album-de-fotos-aRecuperado el 14 marzo de 2021.

${ }^{9}$ Fuera de casos excepcionales, los miembros de las FF.AA. responsables de los delitos cometidos, no han ofrecido datos sobre el destino final de las miles de víctimas desaparecidas, como tampoco han colaborado en la elucidación de las identidades de bebés nacidos en cautiverio e ilegalmente apropiados.

${ }^{10}$ Ministerio de Justicia y Derechos Humanos de la Nación, Argentina.
} 
a los archivos militares ${ }^{11}$, la creación de los equipos de relevamiento y análisis documental ${ }^{12}$ y el programa de modernización del sistema de archivos del área de la Defensa lanzado en el año 2012. Según se comprende, en las encrucijadas de la incansable memoria militante y las políticas aperturistas de archivo, tensionan los comportamientos y responsabilidades ante el pasado cercano.

\section{LA JUNTA: MECÁNICA Y DINÁMICA}

La ley 21.256/76 y su Reglamento, el Acta para la Reorganización Nacional y el homónimo Estatuto, fueron los principales constructos normativos creados para estructurar el poder dictatorial compuesto por las ya aludidas JM, PEN y CAL. Bajo tales encuadramientos, las Actas analizadas indican con claridad que la JM adoptó un esquema de funcionamiento rotativo para la designación de los Secretarios Generales (SS.GG.) de las tres Fuerzas. Sobre ellos recayó la responsabilidad de organizar el temario, coordinar los encuentros que deambularon por distintos edificios gubernamentales ${ }^{13}$, labrar las memorias y llevar adelante las resoluciones adoptadas salvo aquellas que requerían ser implementadas por los ministros de las diferentes carteras canalizadas a través del Secretario General de la Presidencia de la Nación. Una vez confeccionadas y firmadas por triplicado, las actas se enviaban a las restantes armas participantes informando del trámite al Jefe del Estado Mayor Conjunto (EMC).

En mayo de 1977 se aprobaron una serie de modificaciones en la citada ley 21.256 estableciendo, entre otros puntos, un nuevo método de trabajo que sumaba un eslabón burocrático en el circuito: un Oficial Superior de turno y un Suboficial Superior de carácter permanente que, junto al Secretariado, rotaba en sus funciones cada 30 días. La única prerrogativa se fijó para los casos calificados como "estrictamente militares" reservados a la jefatura del Estado Mayor Conjunto $^{14}$. En términos generales, las reuniones sostenidas entre julio de 1976 y noviembre de 1983 se realizaron con metódica regularidad en un promedio quincenal, siendo excepcional el aplazamiento de citas pautadas para cumplimentar con el programa de trabajo.

\footnotetext{
${ }^{11}$ MDNA, Resoluciones $N^{\circ} 173 / 2006$ y N $N^{\circ} 1711 / 2007$.

${ }^{12}$ MDNA, Res. $N^{\circ} 308 / 2010$.

${ }^{13}$ Edificio Libertad, Casa de Gobierno, Edificio Cóndor, entre otros.

${ }^{14}$ Estrategia militar, Defensa Nacional, Planeamiento militar conjunto, etc.
} 


\section{LA TRAMA REPRESIVA}

La planificación sistemática de la represión ilegal del Estado es, sin duda, el capítulo más oscuro de la historia nacional (Águila, 2013; Águila et al., 2016). Por fuera de algunos rebrotes negacionistas registrados en los últimos años (Thus, 2017), un robusto consenso señala a este periodo como el despliegue de un terrorismo de Estado que no tuvo igual respecto de otras etapas igualmente signadas por el autoritarismo. En tal sentido, no debe sorprender que la trama represiva se halle entre los principales temas tratados por la Junta (Fig. 1) según las siguientes problemáticas:

FigURA 1. TEMAS Y PROBLEMAS TRATADOS POR LA JM RELATIVOS A LA REPRESIÓN ESTATAL

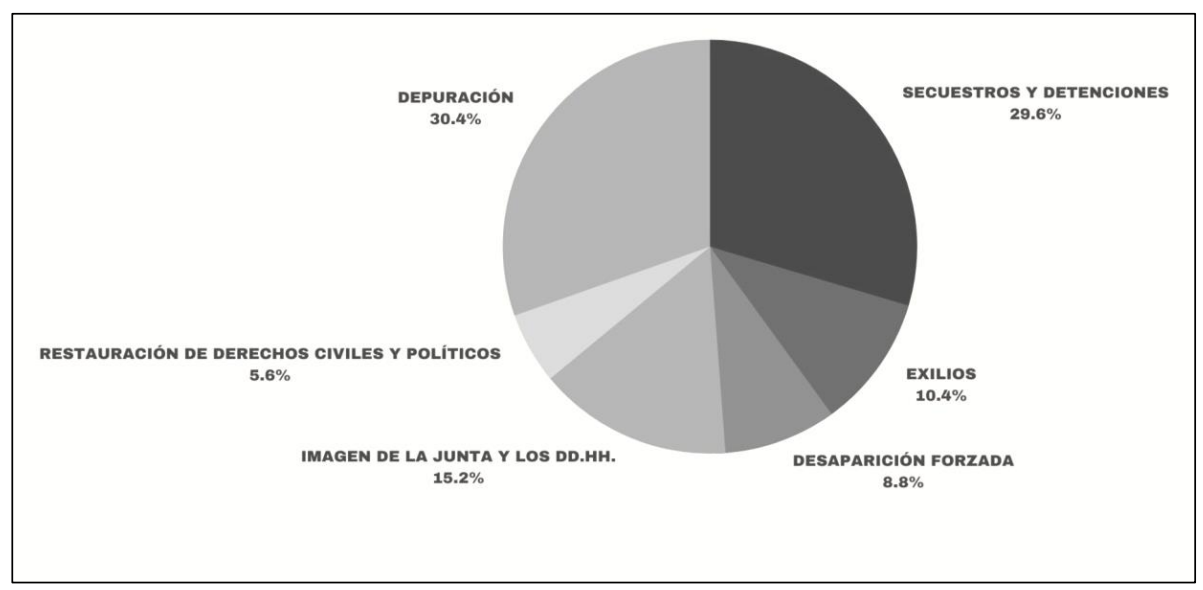

Fuente: Elaboración propia en base a las Actas de la JM (1976-1983)

Las denominadas depuraciones remiten a ciudadanos sobre los cuales se aplicaron sanciones políticas por encontrarlos “(...) responsables de ocasionar perjuicios a los superiores intereses de la Nación"15. Esto es, funcionarios del gobierno democrático anterior prescindidos de sus cargos electivos asentados en las periódicas "actas institucionales". Asimismo, los secuestros y las detenciones políticas o ilegales, solo se apuntan en dichos términos cuando se abordan casos puntuales como el arresto de la ex Presidenta M. E. Martínez de Perón (1974-1976) y/o el paradero de algunos periodistas cuyas historias tuvieron mediana resonancia en el ámbito público. Por regla general, la textura documental sigue la retórica

${ }^{15}$ Resolución $N^{\circ} 4$ del Acta del Proceso de Reorganización Nacional publicada el 18 de junio de 1976. Aplica a personas físicas y jurídicas. 
del lenguaje cavernoso de la inteligencia estatal; en especial, la llamada "fórmula $4 " 16$ emerge en ocasión de dictaminar el destino de presos a disposición del PEN cuyas resoluciones eran apremiantes por razones de salud.

Particularmente, la visita de la Comisión Interamericana de Derechos Humanos en 1979 motivó la revisión de algunos sumarios. Más aún, la presencia del órgano internacional se incorporó en la agenda para ensayar variadas estrategias de neutralización en los medios de comunicación (Iturralde, 2013; Micieli et al., 2016; Pelazas et al., 2019), e impuso reparar con mayor prudencia y gravedad el problema de la "imagen de la Junta y los DD.HH.". En rigor, esto último ya se había manifestado con el ojo público que abrió el Mundial de Fútbol de 1978 (Franco, 2002) y volverá a intensificarse en los meses previos a la apertura democrática en 1983. Estas marcas temporales también se corresponden en una dimensión semántica ligada al crimen más aberrante del periodo: la desaparición forzada de personas. Así, en 1980 o tras la estela de denuncias analizadas por la citada Comisión, la Junta pretendió "desaparecer" dicha categoría y atinar a una noción eficaz que, tras algunas correcciones de oficio, derivó en el acético "pedido de paradero de personas" (Fig. 2), según puede observarse en el siguiente extracto documental:

FIGURA 2. EXTRACTO DOCUMENTAL SOBRE EL TRATAMIENTO DE LA DESAPARICIÓN FORZADA EN 1980

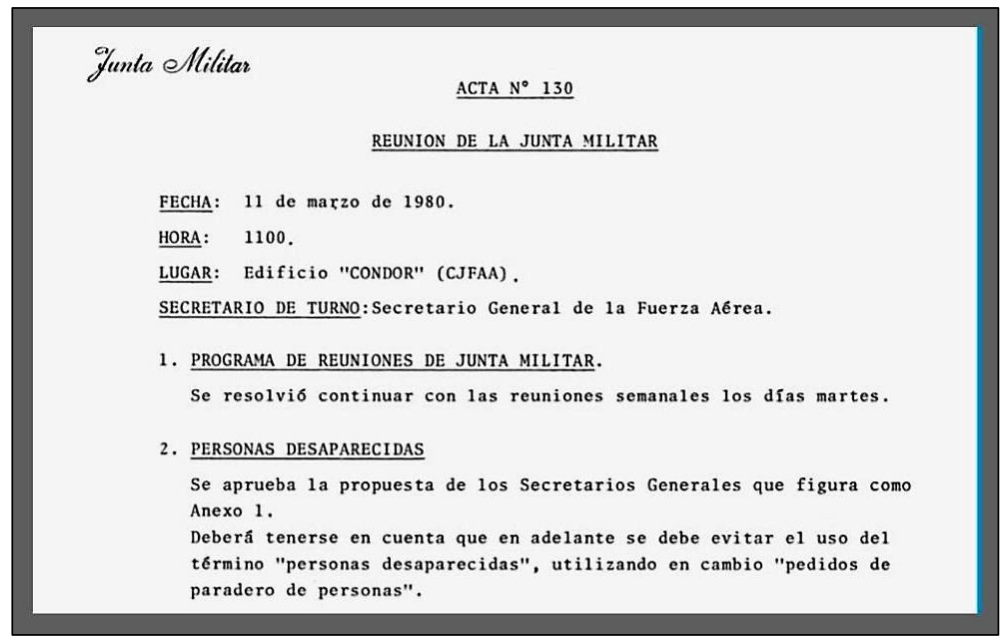

Fuente: Actas, 4, 130: 68, 1980.

16 "Haber incurrido en acciones u omisiones que hayan favorecido la subversión". Actas, V, 234: 77, 1982. 
Ya sobre el año 1983, lo dicho no pudo solaparse definiéndose como una condición "ausente" evidenciada en la falta de evidencia (Fig. 3). En paralelo, se refutaba la existencia de los CCDyT y el lastimoso peregrinar de familiares de desaparecidos y detenidos que, documentalmente, se desliza en contadas solicitudes de audiencia que llegaban a los Secretarios.

FIGURA 3. EXTRACTO DOCUMENTAL SOBRE EL TRATAMIENTO DE LA DESAPARICIÓN FORZADA EN 1983

SECRETO

SE HABLA ASTMISMO dE personas "DESAPARECIDAS" QUE SE ENCONTRARIAN DETENIDAS POR EL GOBIERNO ARGENTINO EN LOS MAS IGNOTOS LUGARES DEL PAIS. TODO ESTO NO ES SINO UNA FALSEDAD UTILIZADA CON FINES POLITICOS, YA QUE EN LA REPU BLICA NO EXISTEN LUGARES SECRETOS DE DETENCION, NI HAY EN LOS ESTABLECIMIENTOS CARCELARIOS PERSONAS DETENIDAS CLANDESTINAMENTE.

EN CONSECUENCIA, DEBE QUEDAR DEFINITIVANIENTE CLARO QUE QUIENES FIGURAN EN NOMINAS DE DESAPARECIDOS Y QUE NO SE ENCUENTRAN EXILIADOS O EN LA CLANDESTINIDAD, A LOS EFECTOS JURIDICOS Y ADMINISTRATIVOS SE CONSIDERARAN MUERTOS, AUN CUANDO NO PUEDA PRECISARSE hASTA EL MOMENTO LA CAUSA Y OPORTUNIDAD DEL EVENTUAL DECESO, NI LA UBICACION DE SUS SEPULTURAS.

Fuente: Actas, 6, 258: 56, 1983.

La problemática de los masivos exilios acaecidos en aquellos años especialmente estudiados en la última década (Lastra, 2018) se registra bajo el ítem "asilados" o se alude a la cuestión con el llamado "derecho de opción" o derecho de optar por salir del país, suprimido por el Estado de Sitio declarado el 26 de marzo de 1976. Su repetido abordaje parece desprenderse de las enmarañadas resoluciones que tuvo en los hechos: un ida y vuelta de aprobaciones y denegaciones particulares a cargo de una Corte Suprema de Justicia enteramente designada por el poder de facto (Bohoslavsky, 2015).

Finalmente, las "restauraciones de derechos" surgen, claro está, en el ocaso dictatorial. Temporalmente, ello se corresponde con un punto de inflexión 
consensuado en la literatura académica: la derrota militar en las Islas Malvinas en 1982 y el sentimiento post-defraudatorio que mutó el clima social hacia una irreversible apertura democrática. Tal escenario se coló con fuerza en la escritura clandestina aunque con diversas intensidades según la dimensión que se analice. En el orden represivo, si bien se relajan algunos de sus mecanismos, proporcionalmente son escasos los documentos que listan la desafectación de personas comprendidas en la "Fórmula 4" u otros registros que decidían nuevas estatutos civiles como el pasaje de la detención a la condición de libertad vigilada.

\section{DOCUMENTOS INSTITUCIONALES}

El ya aludido carácter refundacional del autodenominado PRN, derivó en decenas de documentos políticos en aquellos años. Historiográficamente, estas fuentes suelen utilizarse para introducir los rasgos del periodo seleccionando los comunicados y/o normativas de base lanzados en los primeros meses de 1976. Las Actas halladas en cambio permiten observar la productividad integral en los ocho años que duró el régimen advirtiendo que algunos escritos -sin dejar su talante político- también expresan motivaciones organizativas y/o regulatorias para la administración de la cosa pública (Fig. 4).

FIGURA 4. TEMAS Y PROBLEMAS POLÍTICO-INSTITUCIONALES ABORDADOS POR LA JM

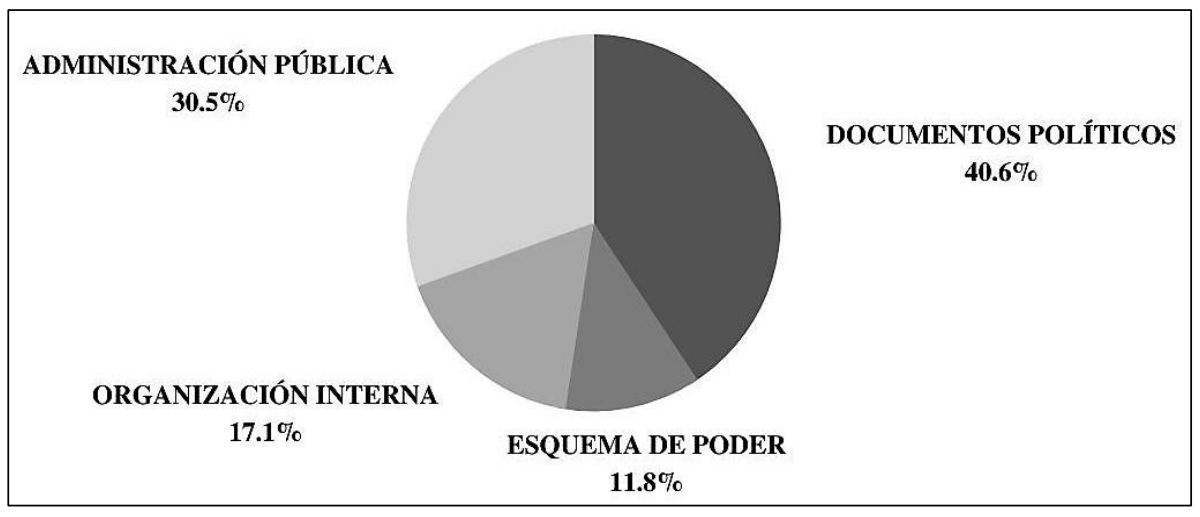

Fuente: Elaboración propia en base a las Actas de la JM (1976-1983).

El gráfico indica que el $40 \%$ del sub-temario "institucional" se halla abocado ininterrumpidamente al programa político con variaciones temporales. El dato en su conjunto evidencia la autopercepción y aspiraciones históricas de forjar un "nuevo ciclo histórico" destinado a lograr cambios sociales permanentes 
y no meramente correctivos (Canelo, 2016). En tal sentido, las posiciones y declamaciones de principios se traducen en directivas de estrategia nacional o en grandes proyectos de trascendencia nacional llevadas a diversas áreas del Estado. Bajo un tenor más pragmático, también se redactan numerosas pautas de acción de gobierno per se o a propósito de la irrupción de conflictos nacionales e internacionales sobre los cuales se pronuncian.

De forma reiterada, igualmente emerge un subgrupo de documentos, por lo regular titulado criterios complementarios, que operan sobre el esquema de poder e incluso alteran la organización interna del órgano recalando en una permanente tensión sobre el aparente equilibrio de fuerzas (Canelo, 2008, 2012a). Con ello, se advierte un tono de sobreactuaciones de equidad tripartita expresadas como: "compatibilización de disidencias", pedidos de "precisiones" sobre diferentes "atribuciones" y "responsabilidad de ejecución" o "unificación de criterios". En varias oportunidades, directamente se alude a la necesidad de "dialogar", "guardar coherencia" o formar un "equipo de compatibilización interfuerzas"17.

En un segundo plano de pretendida institucionalidad, la Junta se propuso "legislar sirviendo a las necesidades del proceso" 18 , para lo cual se analizaron diversos proyectos como la Ley de FONAVI o Fondo Nacional de la Vivienda, la Ley de Asociaciones Profesionales, la Ley de Obras Sociales y la Ley de Radiodifusión finalmente promulgada en 1980 (Elíades, 2003). En su conjunto, los decretos-ley remiten a las siguientes áreas y problemas (Fig. 5):

FIGURA 5. TEMAS Y PROBLEMAS LLEVADOS A PROYECTOS DE LEY TRATADOS POR LA JM

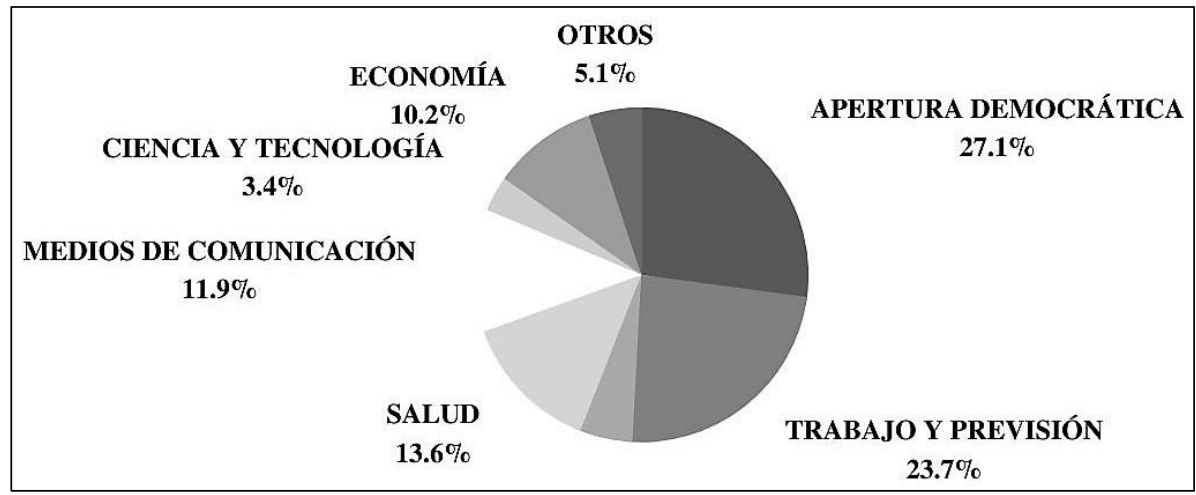

Fuente: Elaboración propia en base a las Actas de la JM (1976-1983).

\footnotetext{
${ }^{17}$ Actas, II, 40: 57, 1977.

${ }^{18}$ Actas, I, 19: 93, 1977.
} 
Sobre este nuevo desgranamiento, resulta fundamental posar la mirada en la legislación planificada a instancias de la apertura democrática. Como ya se ha dicho, tras la derrota en Malvinas el programa castrense viró hacia una organización "de salida" y entrega del poder, atendiendo al asunto más urticante en esta materia: la sanción histórica de "todo lo actuado", según proferían sus responsables. Así, los comandantes dedicaron muchos encuentros al estudio de la paulatina reversión de la prohibición de los partidos políticos y normalización de los gremios intentando imponer condiciones "no negociables" en el futuro cronograma electoral.

\section{Figura 6. EXTRACTO DEL DOCUMENTO DELTA}

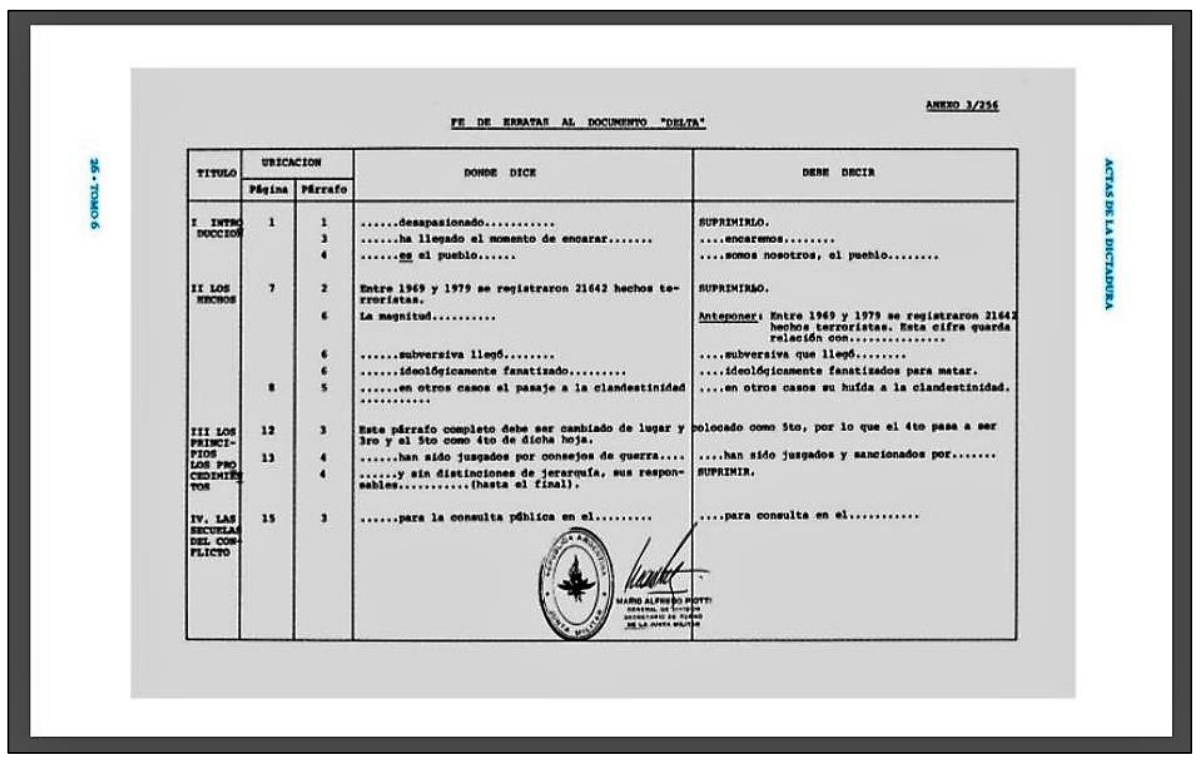

Fuente: Actas, VI, 256: 26, 1983.

A la par, se revitalizó una actividad que había tenido su mayor intensidad en los años 1978-1979: los planes y programas de acción psicológica en un doble seguimiento clandestino: sobre los medios de comunicación y sobre sus propios camaradas para sopesar "(...) los efectos que sobre la unidad de las Fuerzas producen los anuncios de publicaciones que pudieran ser editadas o declaraciones que formulen sus miembros en situaciones de retiro" ${ }^{19}$. En esta dimensión, el denominado documento Delta o "Documento final de la Junta Militar sobre la guerra

${ }^{19}$ Actas, V, 239: 98, 1982. 
contra la subversión y el terrorismo" (Fig. 6), es una fuente cardinal para profundizar un tramo menos explorado en la historiografía: el fin de la ilusión de perpetuarse en el poder. Puntualmente, el archivo permite realizar un examen centrado en las premisas básicas que apuestan a garantizar la impunidad en los inminentes tiempos democráticos, ya fuere por la vía directa del encubrimiento de los delitos cometidos o en la variable indirecta del reconocimiento de unos excesos naturalizados en el marco de una "guerra sucia". Con igual fuerza heurística, los borradores Delta 1, Delta 2 y Delta 3, evidencian las enormes dificultades que tuvieron para lograr una concertación interna.

De esta última etapa nacerán las leyes heredadas al gobierno de Raúl Alfonsín que rigió el país entre 1983 y 1989: Ley de pacificación nacional, Ley de enjuiciamiento de las actividades subversivas y terroristas y Ley de convocatoria a elecciones nacionales y provinciales.

\section{RELACIONES EXTERIORES: EN LOS DOMINIOS DEL BEAGLE}

El escenario internacional ocupa un espacio destacable del temario general. Los sub-temas del área (Fig. 7) se desgranan en los siguientes asuntos:

FiguRA 7. TEMAS y PROBLEMAS DEL ÁREA DE RELACIONES EXTERIORES TRATADOS POR LA JM

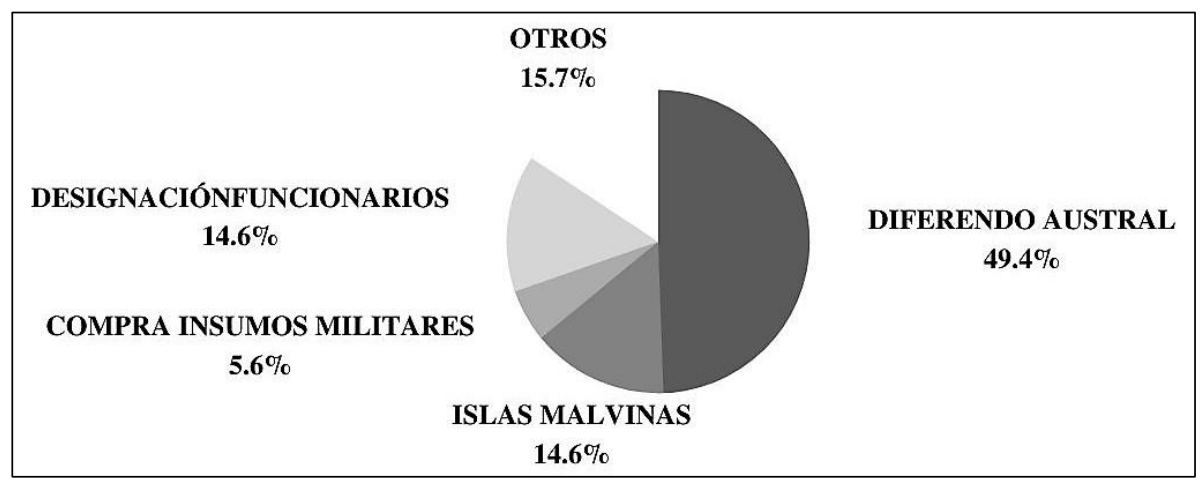

Fuente: Elaboración propia en base a las Actas de la JM (1976-1983).

El Diferendo Austral o litigio sostenido entre Argentina y Chile por las islas al sur del Canal de Beagle consumió gran parte de la agenda exterior, adquiriendo jerarquía documental tras el dictamen de la Corte Arbitral Internacional conocido en Febrero de 1977. Dicha sentencia determinó que las disputadas islas correspondían a la soberanía chilena siendo inmediatamente oficializado con la publicación del laudo británico. En tanto Chile aceptó el resultado, la cancillería 
argentina recibió el oficio sin dar respuesta alguna; vale decir, la llamada "decisión retenida" - como se la denominó en las Actas - se sostuvo por largos meses hasta que finalmente se dictó la nulidad del fallo el 25 de enero de 1978. En los meses siguientes se abrió una insólita escalada belicista que vio sus días de mayor tensión a finales de diciembre del mismo año. Al interior de la Junta también se produjeron notables cambios en el esquema de poder. Concretamente, el Secretariado fue desplazado por el Estado Mayor Central que asimismo respondía al Comité Militar bajo el PEN. Tales movimientos por lejos resultaron intrascendentes, pues políticamente no solo degradaba la supremacía del órgano "haciéndola depender del Presidente de la Nación", ${ }^{20}$ sino que la dinámica viraba en aguas muy agitadas en la disputa inter-fuerzas incluidas las ambiciones personales del Almirante E. Masera a cargo de la Marina (Borrelli, 2008b; Canelo, 2014).

En sintonía, dos sub-temas analizados igualmente derivan de aquel conflicto: la adquisición de insumos militares como los aviones Fokker en 1978 y 1979, y la afinada producción de una propaganda política orientada a la construcción del consenso social. Sin más, el Diferendo Austral resultó uno de los principales móviles de los llamados planes psicosociales del periodo (Risler, 2018; Risler \& Schenquer, 2019; Schenquer, 2019), montados para activar un sentimiento "anti-chileno" que reeditaba viejas tesis fundacionales del S. XIX (Lacoste, 2001, 2002, 2004).

Ahora bien, en tanto el Beagle dominó el programa belicista, el enclave soberano de las Islas Malvinas fue abordado en apenas 13 ocasiones desde 1976. Curiosamente, el tema se halla ausente de las reuniones sustanciadas en los meses de abril y mayo de 1982 cuando tuvo lugar la guerra en el Atlántico Sur, emergiendo accesoriamente la decisión de "mantener el control sobre los bienes radicados en el país de empresas británicas (...) para afectar el patrimonio"21. Al respecto, es posible conjeturar que tal operativa se tramitara en otros ámbitos e instancias burocráticas no siendo entonces capturada por estas Actas. Igualmente, conviene revisar el peso singular del secretismo que aparentemente caracterizó a la planificación castrense en su conjunto. En correspondencia, estas escasas referencias documentales en plena contienda bélica, pueden responder a la fallida estrategia político-militar de "ocupar para negociar"22.

\footnotetext{
${ }^{20}$ Actas, II, 47: 127, 1978.

${ }^{21}$ Actas, V, 221: 46, 1982.

${ }^{22}$ Como bien lo indica el estudio M. Ranalletti: “Todas las investigaciones consultadas coinciden en señalar que jamás se contempló la posibilidad de enfrentar una guerra, sino que las previsiones llegaron sólo hasta la recuperación del territorio malvinense" (2016, s/n).
} 
Por fuera de estas hipótesis, Malvinas adquiere relevancia desde mediados de 1982 y a lo largo de 1983 cuando se inician específicas actividades investigativas. Por un lado, se cita la labor de la Comisión de Evaluación de las Operaciones en las Islas Malvinas creada por el Ejército en junio de 1982 para examinar la conducta del personal de guerra y determinar el honor, la infracción y/o la sanción disciplinaria (Abelenda et al., 2018). Por el otro, se reitera el trabajo de la llamada CAERCAS, o Comisión de Análisis y Evaluación de las Responsabilidades Políticas y Estratégico Militares en el Conflicto del Atlántico Sur, creada a instancias de la JM en diciembre de 1982 y más conocida como Informe Rattenbach.

ECONOMÍA: ENTRE EL CREDO LIBERAL Y LA OPORTUNIDAD INTERVENCIONISTA

La compleja marcha de la economía argentina se tradujo en los siguientes sub-temas sintetizados en el gráfico (Fig. 8):

FIGURA 8. TEMAS Y PROBLEMAS ECONÓMICOS TRATADOS POR LA JM

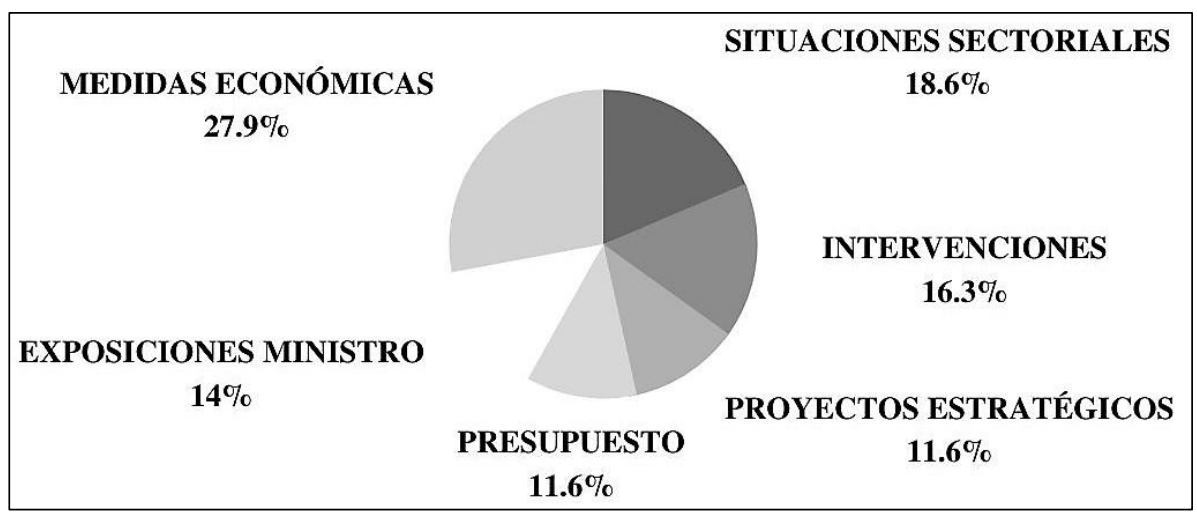

Fuente: Elaboración propia en base a las Actas de la JM (1976-1983)

Para comenzar, el análisis del presupuesto nacional fue introducido por el Secretariado al compás de los informes que presentaba la cartera económica, siendo el área más convocada por la Junta en aquellos años. También se sopesaron variadas medidas económicas y/o salariales ligadas a la indexación de impuestos, a proyectos de privatización de empresas y sociedades del Estado, el incremento de tarifas y la obtención de créditos en el mercado internacional. También se registra el seguimiento de específicas crisis sectoriales como la produc- 
ción azucarera heredada de la dictadura instaurada entre 1966-1971 (Bravo, 2020). Desde ya, lo enumerado amerita una indagación que incluya las veleidades y tensiones entre la JM y el PEN, o ya las disputas entre los ministerios de Economía y Trabajo (Novaro \& Palermo, 2003).

Hacia el final del periodo, los temas se concentraron en los problemas más acuciantes que deberán atenderse con premura en el nuevo gobierno democrático tales como el fuerte deterioro industrial producto de una profunda reestructuración regresiva y ortodoxia aplicada a sangre y fuego (Schorr, 2012), los inéditos índices de la deuda externa contraída (Basualdo, 2016; Rapoport, 2007) y la inflación en ascenso (Basualdo, 1987) ${ }^{23}$.

En un párrafo aparte, es dable señalar la importancia otorgada a los proyectos estratégicos compartidos con países limítrofes. Numerosos anexos transcriben una serie de estudios técnicos, propuestas económicas y negociaciones diplomáticas con Brasil y Paraguay, siendo cardinales las millonarias obras hidroeléctricas de las represas Corpus e Itaipú ${ }^{24}$. En estos casos, los diagnósticos no se ciñen a las tratativas económicas sino que se continúan en una alerta de orden político: un desequilibrio de poder a favor de Brasil dado el liderazgo que cobraba en el Cono Sur. La situación de Itaipú, en particular, visibiliza diferentes posiciones e intercambios que suman al flamante ministerio de Planeamiento (Canelo, 2012b) y regularmente convocado en esta coyuntura. De fondo, resuenan viejas hostilidades y recelos que también se manifestaban en los discursos públicos como una verdadera guerra fría (Madrid, 2011). En los momentos de máxima tensión, acaso atenazados por la esterilidad de las negociaciones, la Junta no descartaba "el apelar a recursos de mayor dureza si nuestros interlocutores nos enfrentaran a actitudes intransigentes o irracionales" 25 .

Finalmente, la historiografía ha dado sobradas muestras de la impronta neoliberal que caracteriza las políticas económicas mayoritariamente ejecutadas por el ministro Alfredo Martínez de Hoz entre 1976 y 1981, dando paso a un nuevo régimen de acumulación y concentración bajo un modelo rentístico-financiero que, desde ya, profundizó el disciplinamiento social (Gerchunoff, 2020). No obstante, también se efectivizaron acciones netamente intervencionistas sobre

\footnotetext{
${ }^{23}$ Entre 1976 y 1983, la deuda externa creció de 8.085 a 45.087 millones de dólares. Para el mismo periodo, la inflación trepó de $182.6 \%$ anual a $343.3 \%$.

${ }^{24}$ Corpus es una central hidroeléctrica proyectada sobre el río Paraná entre la Argentina y el Paraguay. Su proyecto de creación nace en los años '60 deteniéndose las negociaciones durante las dictaduras en ambos países. Por su parte, la represa de Itaipú se sustanció con la firma del Acuerdo Tripartito entre Brasil, Paraguay y Argentina en 1979.

${ }^{25}$ Actas, II, 48:157, 1978.
} 
organismos y empresas públicas y/o sociedades privadas. Al respecto, las fuentes listan un total de 30 empresas de diversa naturaleza comercial que sufrieron el sistemático bloqueo de cuentas bancarias por vía de interdictos y/o resultaron inhabilitadas, derivando en gravosos quebrantos patrimoniales. En esta misma trama, se sitúa la paradigmática transferencia de acciones de "Papel Prensa" y otras empresas del Grupo Graiver (Borrelli, 2008a, 2011), configurándose la comisión de violaciones a los DD.HH. en un doble plano: delitos económicos y crímenes de lesa humanidad sobre sus propietarios/as ${ }^{26}$.

\section{PROTOCOLO Y FAMILIA MILITAR: LA IMPORTANCIA DEL DETALLE Y LA CORPORACIÓN}

Un dato curioso resulta de la relevancia documental que adquieren los asuntos protocolares (Fig. 9) segmentados en:

FIGURA 9. TEMAS Y PROBLEMAS PROTOCOLARES ABORDADOS POR LA JM

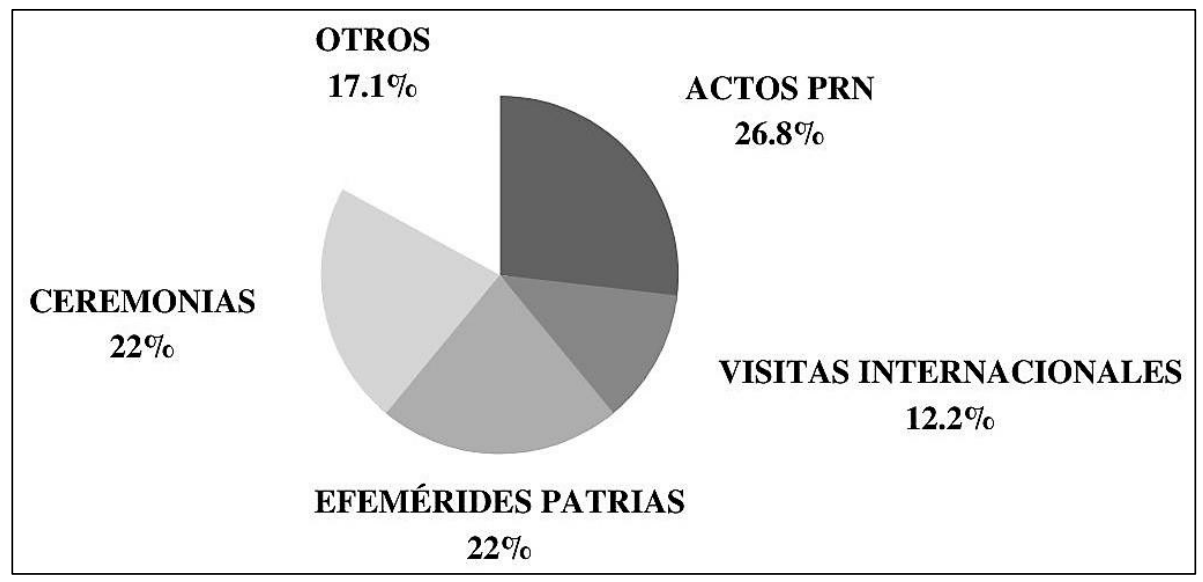

Fuente: Elaboración propia en base a las Actas de la JM (1976-1983).

Las solemnes ceremonias como los juramentos militares y/o actos en torno de las fechas patrias, se revisaron y coordinaron al detalle. En esta variante se suma una nueva efeméride: el aniversario y las celebraciones del PRN. Así,

\footnotetext{
${ }^{26}$ El titular de Papel Prensa S. A., D. Graiver, falleció el 6/10/1976 en un confuso accidente aéreo. Algunos meses después, la esposa del empresario, L. Papaleo, y el vicepresidente, R. Ianover, (convertidos en accionistas mayoritarios), sufrieron hostigamiento, detención ilegal y torturas. Durante su cautiverio, se firmó el traspaso accionario a una sociedad llamada "Fapel", integrada por los diarios Clarín, La Nación y La Razón. En función del nuevo armado comercial, la Junta acordó una serie de instrucciones precisas que se traducen en la reiteración del tema en su agenda.
} 
cada 24 de marzo resulta una fecha que trágicamente parodia una sesión extraordinaria de la Asamblea Legislativa en tiempos democráticos. De igual modo, se registran los comunicados publicados para las festividades de fin de año o en ocasión del "día del periodista". Especialmente, se destacan las pomposas visitas internacionales cuyas reglas de etiqueta se compaginaban con la jerarquía y cadena de mandos; tales son los casos de la llegada del Rey de España en 1978 y de Juan Pablo II en 1982 (Guillemont, 2018).

Otra singularidad hallada resulta de las cuantiosas reuniones destinadas a los asuntos de la "familia militar" (Fig. 10); un especial tratamiento temático para la resolución de un conjunto de problemas que redundan en beneficios exclusivos de "sus hombres". A saber:

FIGURA 10. TEMAS Y PROBLEMAS DEL ÁMBITO ESTRICTAMENTE MILITAR ABORDADOS POR LA JM

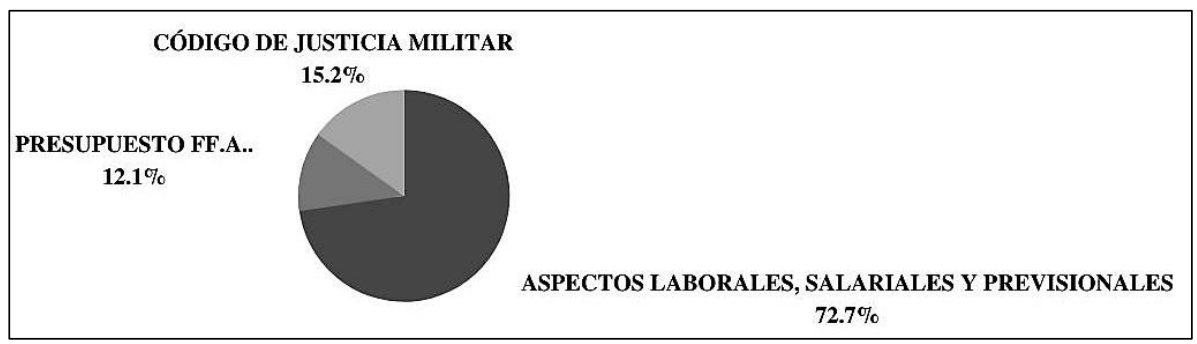

Fuente: Elaboración propia en base a las Actas de la JM (1976-1983).

Mayoritariamente, se abocan a temas salariales y laborales que redundan en reintegros de gastos al personal militar, reajustes de haberes a las FF.AA., remuneraciones especiales y subsidios extraordinarios; entre otros. En paralelo, las partidas del presupuesto nacional destinado al área se gestionan como un asunto en particular. También, se subsanan situaciones del personal que tramitaban su retiro o revestían en regímenes jubilatorios incompatibles. Precisamente, sobre los últimos meses de 1983, se conformaron comisiones que proponían actualizaciones sobre las normativas existentes. Finalmente, en contadas ocasiones la Junta interfiere en los sumarios estudiados por la justicia militar relativos a problemas disciplinarios, personal bajo proceso o querellas a cargo del Tribunal de Honor. 


\section{LA EDUCACIÓN EN LA AGENDA DE LOS COMANDANTES}

Las áreas educativas y culturales (Fig. 11) fueron tratadas en 23 ocasiones estrictamente dedicadas a:

FIGURA 11. TEMAS Y PROBLEMAS EDUCATIVOS ABORDADOS POR LA JM

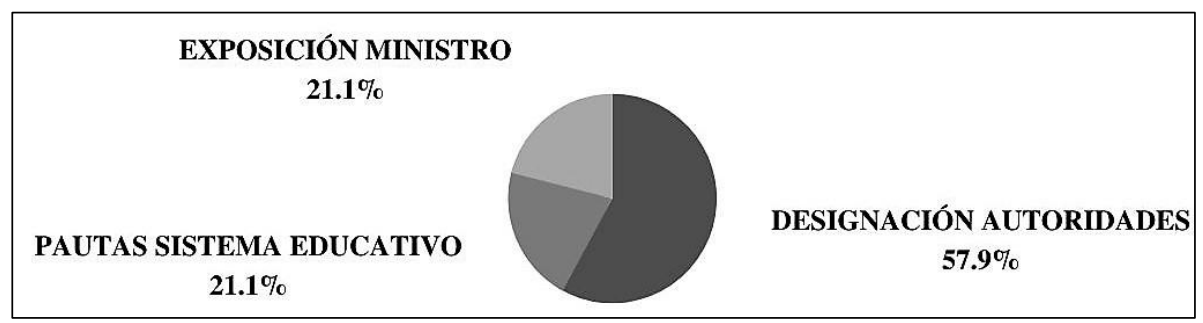

Fuente: Elaboración propia en base a las Actas de la JM (1976-1983).

La designación y/o recambio de autoridades es el ítem dominante en esta dimensión y en lo particular del nombramiento de Rectores y Decanos interventores-normalizadores en variadas universidades del país ${ }^{27}$. Solo el caso de la Universidad de Buenos Aires se trató en más de un encuentro a la espera de los antecedentes político-ideológicos de los postulantes reunidos por los organismos de inteligencia.

Este tipo de oficios también incluyó el cese del delegado de la JM en la cartera educativa nacional en 1977 y el repentino alejamiento del ministro Prof. Ricardo Bruera en abril del mismo año. En el primer caso, las fuentes indican que su desplazamiento se debió a una propuesta presentada por el Ejército ${ }^{28}$. En cuanto a Bruera, solo se menciona su renuncia sin despejar razones que nos permitirían reconsiderar las hipótesis ensayadas en otros trabajos ligadas a su proyecto pedagógico (Tedesco et al., 1983) o por razones presupuestarias (Rodríguez, 2015).

Finalmente, para esta área se suman anexos que explicitan los principios y características del modelo educativo o pautas para la educación ordenadas en una serie de descriptores generales, tales como racionalidad, adaptabilidad, subsidiariedad, regionalización, educación permanente, Familia-Estado-Iglesia y competitividad. Al respecto, puede decirse que los diagnósticos sistémicos y particulares de cada nivel de enseñanza, los encuadres y fundamentos políticos, el conservadurismo moral y moralizante, los objetivos pedagógicos y funda-

\footnotetext{
${ }^{27}$ La Plata, Bahía Blanca, Lomas de Zamora, Mendoza, Córdoba, Río Cuarto, Misiones, San Juan, San Luis, Catamarca y Luján.

${ }^{28}$ Actas, I, 20: 98; 21: 99, 1977.
} 
mentos epistemológicos, la tendencia tecnocrática y el declarado rol subsidiario del Estado, no aportan demasiada originalidad a la historiografía educativa, según lo hemos relevado en otro trabajo (García, 2019).

\section{CONCLUSIONES FINALES}

Las Actas exploradas testimonian la letra decisoria del máximo órgano responsable de la última dictadura argentina. El examen y sistematización de estos materiales nos permitió identificar sus prioridades temáticas según las diferentes áreas de gobierno, problemáticas nacionales y coyunturas atravesadas (Fig. 12), reunidas en una serie de categorías que derivaron en los siguientes porcentajes:

FiguRA 12. DisTRIBUCIÓN DE TEMAS EN LA AGENDA DE LA JM

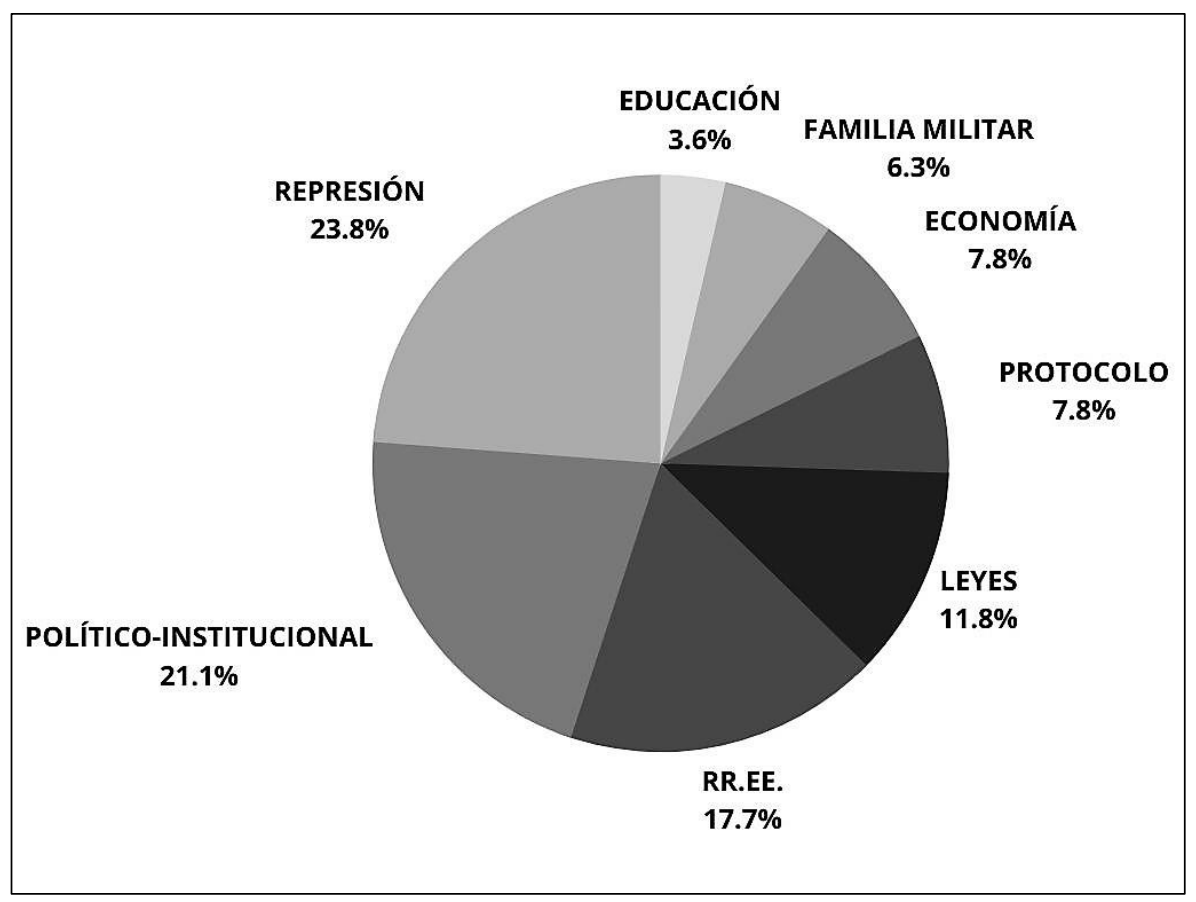

Fuente: Elaboración propia en base a las Actas de la JM (1976-1983).

La represión ilegal encabezó la agenda de trabajo en sus diferentes instancias y variantes destinadas a la persecución, expulsión, detención y ya exterminio de actores y sectores considerados subversivos. Con igual intensidad, también se abocó al cuidado de la imagen pública con el objeto de neutralizar la sospecha de una sistemática violación a los DD.HH. En particular, la llegada de la Comisión 
Interamericana de Derechos Humanos a la Argentina en 1979 imprimió su huella documental al constatarse que en dicho año se da la mayor saturación temática en esta categoría.

Un inmediato segundo lugar lo ocupan los documentos políticos del PRN. A diferencia de otros acervos, estas fuentes dejan ver la continua productividad que va traduciendo los principales rasgos del régimen: su carácter fundacional, las trascendentales aspiraciones históricas, los frecuentes cambios sobre el edificio burocrático ligado al esquema de poder y el permanente problema del internismo castrense. En esta dimensión, la mayor proliferación de fuentes se concentra en el año 1983 sumando la categoría Leyes. Al respecto, bien puede decirse que el Terrorismo de Estado no solo tuvo una planificación de entrada sino de salida, traccionada por la atmósfera antidictatorial que se instaló a mediados de 1982. Las escrituras desnudan entonces una nueva semántica ensayada por la JM a los efectos de garantizar olvido e impunidad; una plataforma de autocríticas vacías y andamiajes a base de tecnicismos que la dispense de futuros estrados judiciales. Bajo el mismo espíritu corporativo, un significativo $6 \%$ de la agenda se dedicó estrictamente a la familia militar.

Ahora bien, la trascendental marcha de la economía argentina y los intrascendentes asuntos protocolares, llamativamente se igualan en sus porcentajes. En sintonía, un área gravitante como la educación, apenas fue incluida en una veintena de reuniones que en gran medida se agotaron en los primeros meses de 1976. Sobre dicha información, ¿qué lecturas deberían ensayarse?

Por lejos se sugiere un análisis lineal de los datos sintetizados, a sabiendas de que ninguna potencia heurística atrapa la totalidad y fidelidad de lo realhistórico. Tal es el caso del sistema educativo argentino en dicho periodo, cuyo control y depuración autoritaria fueron gestionados desde un complejo y ordenado reparto de agentes y actores que revistaron en específicas burocracias intervinientes según los territorios y las jurisdicciones. Reparar en la existencia de mencionado edificio material y simbólico, cambia la perspectiva de la magra dedicación de la Junta, como tampoco es una muestra de desinterés del régimen sobre este campo.

Lo antedicho nos retorna a las reflexiones sobre el publicitado hallazgo de las Actas en el año 2013. Sin desestimar la innegable significancia del hecho, es importante renunciar a la ilusión de dar con un acervo definitivo o un documento final sobre el periodo. A nuestro entender, allí se produce una suerte de espejismo que remite a la huella traumática legada por el signo histórico de la desaparición. Si se quiere, la imposibilidad de un duelo ante la ausencia de la 
corporalidad, tiene su correlato en los archivos toda vez que se anhela hallar la escritura confesional de sus ideólogos. Por delante solo resta lo hasta aquí realizado desde el retorno a la democracia: avanzar en la tarea historiográfica de conectar grandes porciones de realidad que el terrorismo de Estado, como tal, desdobló con crueldad. Después de todo, el verbo "hallar" hunde sus raíces en el vocablo fallar, es decir, "echar aliento hacia algo...".

\section{REFERENCIAS}

Abelenda, F., Lavintman, J., \& Villalba, V. (2018). Documentos sobre la guerra de Malvinas en los archivos del Ejército: Una metodología de trabajo. http://conti.derhuman.jus.gov.ar/2018/01/seminario/mesa_22/abelenda_lavintman_villalba_mesa_22.pdf

Águila, G. (2013). La represión en la Historia Reciente argentina: Perspectivas de abordaje, conceptualizaciones y matrices explicativas. Contenciosa, (1), 1-14. http://dx.doi.org/10.14409/contenciosa.v0i1.5043

Águila, G., Garaño, S., \& Scatizza, P. (2016). Representación estatal y violencia paraestatal en la historia reciente argentina: Nuevos abordajes a 40 años del Golpe de Estado. UNLP.

Balé, C. (2018). Usos del archivo y políticas de la memoria: Un análisis del proceso de "apertura" de los archivos militares en Argentina (2003-2015). Nuevo Mundo Mundos Nuevos. https://doi.org/10.4000/nuevomundo.73860

Basualdo, E. (1987). Deuda externa y poder económico en la Argentina. Nueva América.

Basualdo, E. (2016). La política económica de la dictadura militar. Siglo XXI.

Borrelli, M. (2008a). Una batalla ganada: El diario Clarín frente a la compra de Papel Prensa por parte de los diarios La Nación, Clarín y La Razón (1976-1978). Papeles de trabajo: La revista electrónica del IDAES, (4), 2-17.

Borrelli, M. (2008b). El diario Convicción: Entre Massera y la Marina. Trampas de la Comunicación y la Cultura, (59), 64-68.

Borrelli, M. (2011). Voces y silencios: La prensa argentina durante la dictadura militar (1976 1983). Perspectivas de la comunicación, (1), 24-41.

Bohoslavsky, J. P. (2015). ¿Usted también, Doctor? Siglo XXI.

Bravo, M. C. (2019). Los cañeros ante el colapso de la industria azucarera tucumana en la década de 1960. En J. M. Cerdá \& G. Mateo (Coord.), La ruralidad en tensión. TeseoPres. https://www.teseopress.com/ruralidad/chapter/los-caneros-ante-el-colapso-de-la-industriaazucarera-tucumana-en-la-decada-de-1960-protestas-cupos-de-produccion-y-diversificacion-de-cultivos

Canelo, P. (2008). El proceso en su laberinto: La interna militar de Videla a Bignone. Prometeo.

Canelo, P. (2012a). Los efectos del poder tripartito. La balcanización del gabinete nacional durante la última dictadura militar argentina. Prohistoria, (17), 129-150.

Canelo, P. (2012b). Los desarrollistas de la 'dictadura liberal': La experiencia del Ministerio de Planeamiento durante el Proceso de Reorganización Nacional en la Argentina. Anos 90, (35), 169-190. 
Canelo, P. (2014). La política contra la economía: Los elencos militares frente al plan económico de Martínez de Hoz durante el Proceso de Reorganización Nacional (1976 1981). En A. Pucciareli (Coord.), Empresarios, tecnócratas y militares: La trama corportativa de la última dictadura (pp. 219-312). Siglo XXI.

Canelo, P. (2016). La politica secreta de la última dictadura argentina (1976-1983). Edhasa.

Canelo, P., \& Franco, M. (2015). Las 'Actas de la dictadura' y la revitalización de los estudios sobre el Proceso de Reorganización Nacional. Defensa Nacional y Pensamiento Estratégico, (2), 84-85.

Canelo, P., Franco, M., \& Manzano, V. (2016). Introducción al dossier Dictadura y Estado. Papeles de Trabajo, (17), 13-28.

Da Silva Catela, L. (2002). El mundo de los archivos. En E. Jelin \& L. Da Silva Catela (Eds.), Los archivos de la represión: Documentos, memoria y verdad (pp. 195-219). Siglo XXI.

Elíades, A. (2003). Historia legal de la radio y la televisión en Argentina. Oficios terrestres, (13), 32-56.

Franco, M. (2002). La “campaña antiargentina”: La prensa, el discurso militar y la construcción de consenso. En J. Casali de Babot y M. Victoria Grillo (Eds.), Derecha, fascismo y antifascismo en Europa y Argentina, (pp. 195-225). Universidad Nacional de Tucumán.

Franco, M. (2014). El complejo escenario de la disolución del poder militar en la Argentina: la autoamnistía de 1983. Contenciosa, (2), 1-18. http://dx.doi.org/10.14409/contenciosa.v0i2.5057

García, N. (2019). Historiografía y memorias en la educación argentina reciente: balances políticosacadémicos y aportes desde un estudio de caso. Perspectivas e Diálogos: Revista de História Social e Práticas de Ensino, (3), 173-198.

Gerchunoff, S. (2020) Intelectuales neoliberales de la economía durante la última dictadura argentina: Construcción de hegemonía en la formación de un nuevo régimen de acumulación (1976-1983). Revista De Historia Americana y Argentina, (2), 207-239.

González Quintana, A. (1998). Los archivos de la seguridad del Estado de los desaparecidos. https://www.foroporlamemoria.info/excavaciones/archivos_represion.htm

Guillemont, M. (2018). La prensa escrita argentina y la visita oficial del rey a la junta militar en 1978. Individu \& nation, (6). https://preo.u-bourgogne.fr/individuetnation/index.php?id=354\#quotation

Invernizzi, H., \& Gociol, J. (2003). Un golpe a los libros: Represión a la cultura durante la última dictadura militar. Eudeba.

Iturralde, M. (2013). El diario Clarín y la visita de la CIDH a la Argentina (1979-1980): Silencio estratégico y reposicionamiento editorial. Questión, (37), 316-327.

Lacoste, P. (2001). Chile y Argentina al borde de la guerra (1881-1902). Anuario del CEH, (1), 302-328.

Lacoste, P. (2002). La guerra de los mapas entre Argentina y Chile: Una mirada desde Chile. Historia, (35), 211-249. https://dx.doi.org/10.4067/S0717-71942002003500009

Lacoste, P. (2004). La disputa por el Beagle y el papel de los actores no estatales argentinos. Revista Universum, (19), 86-109. https://dx.doi.org/10.4067/S0718-23762004000100005 
Lastra, M. S. (2018). Exilios: un campo de estudios en expansión. CLACSO. https://doi.org/10.15848/hh.v13i33.1578

Madrid, E. (2011). Argentina y Brasil: Economía y política exterior bajo regímenes dictatoriales, 1976-1983. Ciclos en la historia, la economía y la sociedad, (37), 1-32.

Micieli, C., Pelazas, M., \& Mira. E. (2016). Torcidos e inhumanos: Ppuntes sobre el rol de la prensa política adicta durante la visita de la CIDH en 1979. Casos: "Extra" y "Creer" dirigidas por Bernardo Neustadt y "Carta Política”, dirigida por Mariano Grondona. Revcom, (3), 170-181.

Nazar, M. (2007). Dictadura, archivos y accesibilidad documental: A modo de agenda. Derechos humanos en Argentina: Informe 2007. CELS.

Novaro, M., \& Palermo, V. (2003). La dictadura militar 1976/1983: Del golpe de Estado a la restauración democrática. Paidós.

Pelazas, M., Micieli, M. C., Mira, M. E., Salmún Feijóo, G., \& Picotti, G. (2019). ¿Dónde están las víctimas? ¿Quiénes son? Análisis de la trama negacionista militar en Argentina. Avatares de la comunicación y la cultura, (17),1-24.

Ranalletti, M. (2016). Jamás pensé que los argentinos serían tan locos: La planificación de la recuperación de las islas Malvinas en 1982 frente al legado de la represión ilegal. Amerika. https://doi.org/10.4000/amerika.7691

Rapoport, M. (2007). Mitos, etapas y crisis en la economía argentina: Nación - Región- Provincia. En M. Rapoport \& H. Colombo (Comp.) Pensamiento político, económico y social (pp. 9-37). Vice gobernación de Catamarca; Imago Mundi.

Ricoeur, P. (2004). La memoria, la historia, el olvido. Fondo de Cultura Económica.

Risler, J. (2018). La acción psicológica: Dictadura, inteligencia y gobierno de las emociones 1955-1981. Tinta Limón.

Risler, J., \& Schenquer, L. (2019). Guerra, diplomacia y producción de consenso: El plan de acción psicológica del Ejército argentino en el marco del conflicto con Chile por el Canal de Beagle (1981-1982). Revista Universitaria de Historia Militar, (17), 48-70.

Rodríguez, L. (2015). Universidad, peronismo y dictadura (1973-1983). Prometeo.

Schenquer, L. (2019). Los usos de la cultura en la última dictadura argentina (1976-1983): De los estudios en postdictadura sobre el control represivo a los análisis más recientes sobre la construcción de consensos. Latin American Perspectives, (20), 1-16.

Schorr, M. (2012). La desindustrialización como eje del proyecto refundacional de la economía y la sociedad en Argentina, 1976-1983. América Latina en la historia económica, (3), 31-56.

Tedesco, J.C., Carciofi, R., \& Braslavsky, C. (1983). El proyecto educativo autoritario: Argentina, 1976-1982. Miño y Dávila.

Thus, V. (2017). Negacionismo y políticas públicas: ¿Encarna Argentina un negacionismo estatal? Revista Crítica Penal y Poder, (13), 185-207. 